\title{
Professional Services and RuRal SERVICES POVERTY
}

\author{
PAUL MARTin* \\ JACQUELINE WILLIAMS** \\ AMANDA KENNEDY ${ }^{* * *}$
}

It is a fact that rural people suffer from professional services deprivation relative to their urban counterparts. Access to legal services is one form of this deprivation. Whilst often understood as a workforce problem, the issue has broader implications for the economic and social welfare of communities and the professionals who try to serve their needs. In particular the inability to access sufficient 'knowledge services' lies at the heart of many problems of rural social exclusion, the cost of which falls inevitably on those who are less mobile, or less capable of securing wealth. This paper takes a systemic look at rural professional services delivery, placing legal services in their larger context as part of the (often incomplete) professional network that supports communities. It outlines the systemic problem and aspects of the specific issues for rural professional services. It presents the results from a survey and a summit organised to discuss the issues that span various professions, and outlines some of the directions that the legal profession might take.

\section{The Aims Of the PAPER}

Approaching a decade ago, one of the authors of this paper was retained by the Law Society of NSW (with others) to consider the future of legal services delivery in the light of national competition policy (NCP). This was partly due to the authors' previous explorations of the extent to which the competitive

\footnotetext{
* Professor and Director, Australian Centre for Agriculture and Law, University of New England.

** Senior Researcher Australian Centre for Agriculture and Law, University of New England.

*** Deputy Director, Australian Centre for Agriculture and Law, University of New England, Australia.
} 
landscape (and viability) of legal practice was changing. ${ }^{1}$ The conclusions of the Law Society study are worth revisiting as a preamble to this paper:

Whilst acknowledging that NCP is leading the breakdown of anticompetitive traditional institutions it is important to also acknowledge that markets tend to serve the strong, and leave the weak unsupported. In a civil society that outcome is rarely seen as a desirable outcome, and initiatives are taken to ensure that social equity is maintained. As we have outlined in this paper, there are strong arguments in theory and indications in practice, that further initiatives are required alongside competition policy to better look after the interests of rural and regional communities, small business, and those who are suffering economic or other disadvantage.

Most professions have arrived at a position where doctrinaire resistance to competition policy is not the agenda. Most accept that competition offers consumer benefits, and that part of the cost of this benefit will be borne by the members of the profession who are unable to compete effectively. Where the legitimate discomfort arises is with the idea that a large part of the costs of the improved outcomes for the successful may come at the cost of substandard outcomes for the disadvantaged.

The ability of practitioners in less advantaged fields of work to afford the time to serve the less advantaged has, it would seem, often been the result of hidden cross subsidies within professional practice. Standard fee scales and limits on entry to the market do result in some service users paying more, but it is the 'tax' of these service users that permits the 'subsidy' that is provided to those who cannot be profitably served. Without that cross subsidization, it is not viable to serve many parts of the market, and this is evident in the emerging patterns of service provision for many professions.

Redressing this issue does not require reversing competition policy. It does however require consideration of what can be done to ensure services will be supplied when there is no market. In other areas of policy importance, such as environmental sustainability, the response has been to create markets.

1 Paul Martin, 'What Future for the Legal Profession? Strategies for Adaption and Reconstruction of the Legal Profession in NSW' (Monograph, Law Society of New South Wales, April 1994); Paul Martin, 'Perspectives on the Future of a Profession under Reform' (1993) 31(5) Law Society Journal 49; Paul Martin, 'An Agenda for Change - Current Challenges and Future Directions of the Legal Profession' (1993) 31(4) Law Society Journal 48 . 
This paper argues that it is about time we as a society seriously consider what can be done to create a market for professional services for the less advantaged. $^{2}$

In the intervening period a great deal of work has been done to address the needs of those who are disadvantaged in access to legal services because of socio-demographic or locational considerations. In particular we have seen the impetus for Aboriginal Legal Centres and Legal Aid continue (albeit that these are continually under-resourced), with the addition of initiatives such as Tenancy Advocacy, Alternative Dispute Resolution, Circle Sentencing, and the like. Such initiatives parallel what has occurred in relation to other aspects of disadvantage and access to a variety of professional services, particularly in health and education. However, notwithstanding sometimes heroic efforts within disciplinary 'silos', the indications are that the undesired state of affairs that was predicted a decade ago has come to fruition, and that the least advantaged people in the most isolated situations remain marginalised in their access to legal and other services even whilst market competition has increased and services to the privileged (and income to those who serve the privileged) are readily seen as having improved.

This then suggests the question, 'What ought to be done about this?' A decade and a variety of interactions with law and other professions have shifted the authors' thinking. The problem is both intra-professional, and systemic across all rural professionals. Our recommendations in 2001 focused on arrangements within the legal profession, and these recommendations have been echoed in other studies. Our more recent work has suggested that these innovations will not in themselves be effective unless there are also systemic interventions that span a variety of professions. Professions are not species of experts operating against the background of their own professional communities; they are rather components in an economic and social ecosystem, and unless the system is healthy and has a sufficient richness of species interacting with vibrancy the individuals are unlikely to survive and be productive.

It is to the additional component of creating (or hopefully preserving) system robustness that this paper is largely addressed. In it we hope to identify those components of a strategy to improve rural access to legal services that are specific to the profession, and those that require a shared approach across a variety of professions in partnership with rural communities and government.

\footnotetext{
2 Paul Martin, Miriam Verbeek, Robert Marks, 'National Competition Policy: Planning the Second Wave: Future Directions in the Reform of Legal Services Delivery' (Discussion Paper, Law Society of New South Wales, April 2002).
} 
It draws particularly on research conducted as part of the University of New England's 'Rural Resurgence' programme, the focus of which is systematic intervention to improve the social inclusion of rural people, by supporting better access to knowledge and information that can better enable them to participate equally with their urban peers in the opportunities available from society.

\section{The Problem of Legal Services Supply}

In the earlier Law Society study we identified some of the patterns of legal supply, from a variety of sources. Based upon practising certificate data for NSW (2001-2002) it was possible to discern a pronounced pattern of country legal practitioners being materially older than their peers in city or suburban practice; and from national statistics it was possible to see that there was negligible net recruitment into the ranks of rural legal practice but appreciable growth in the number of lawyers in urban practice. The picture was one of a robust urban legal services sector serving the needs of those who are privileged, and a rural legal sector with an over-representation of practitioners approaching retirement.

The more recent literature review by Trish Mundy for the Northern Rivers Community Legal Centre brings some of this information up to date. Some quotes from this report serve broadly to illustrate the commonality of the findings:

The findings of a recent 'mapping project' indicate that over the past decade there has been a significant movement of private solicitors away from inland areas of NSW towards coastal areas of the state. Further, those private solicitors who continue to be located outside of city and suburban areas have become more concentrated in the larger regional centres. This has meant that for many in the smaller and more inland communities, access to lawyers is made particularly difficult.

The recruitment and retention of lawyers in the private sector has arguably been affected by the application of competition policy to the legal profession along with a reduction in resources to legal aid and the overall effects of 'rural decline' in many areas. These factors have impacted on the continued viability of rural practice. This is because rural practices are more reliant on work in key areas which face substantial competitive pressures, such as conveyancing, wills and estates and family law. In addition, Legal Aid is no longer available in areas it once was and so is no longer a source of income for many practices. Added to these factors are the increased costs 
associated with rural practice, such as travel and disbursements. There is some evidence that the size and number of firms in country areas are falling. ${ }^{3}$

That report additionally draws attention to the gender composition of rural versus urban legal practice, indicating an additional dynamic not apparent a decade ago - the significance of the relative unattractiveness of rural legal practice to women who now form the bulk of new solicitors. To provide a statistical insight into the shifts that are occurring within this overall pattern, we set out below a graph that compares NSW practising certificate data in $2001^{4}$ and similar data for $2007,{ }^{5}$ which highlights the continued decline in rural practice and the increase in suburban, government and corporate practice and (particularly) of female solicitors.

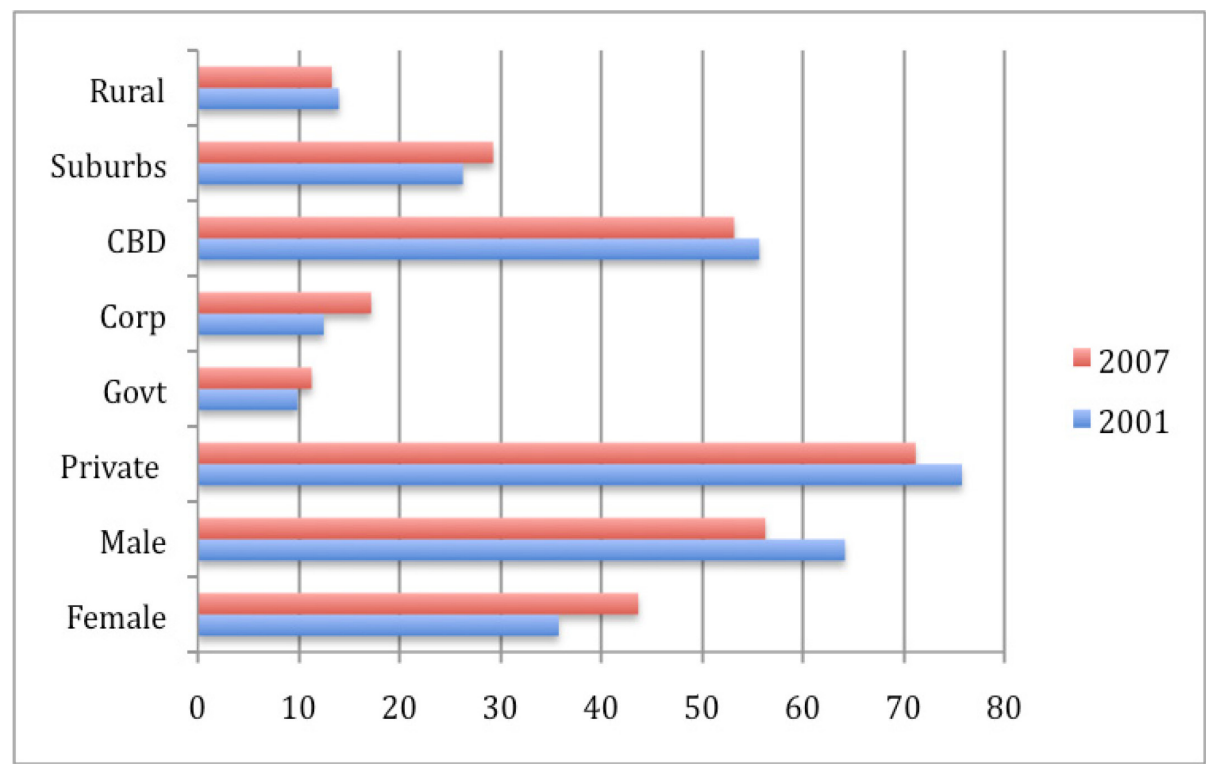

2007 data in upper bars, 2001 beneath.

${ }^{3}$ Trish Mundy, 'Recruitment and Retention of Lawyers in Rural, Regional and Remote NSW' (Literature Review, Northern Rivers Community Legal Centre, July 2008) 2-3<http://www. nrclc.org.au/SiteMedia/w3svc728/Uploads/Documents/RecruitmentRetentionOfLawyers. pdf $>$.

${ }^{4}$ Law Society of New South Wales, '2001 Profile of the Solicitors of New South Wales' (2001) $<$ http://www.lawsociety.com.au/idc/groups/public/documents/internetcontent/026053 .pdf $>$.

${ }^{5}$ Urbis Keys Young, '2007 Profile of the Solicitors of New South Wales' (Law Society of New South Wales, December 2007) <http://www.lawsociety.com.au/idc/groups/public/documents/ internetcontent/026046.pdf $>$. 


\section{A Immediate Effects and Causes}

There has been no careful study of the effects of the limited and ageing supply of lawyers in rural areas compared to that in urban communities. This is a significant failing in the discussion, and it reflects a broader lack of understanding of the tangible benefits of the law to society, which leads to a focus on that which is measurable - the costs of achieving that unspecified benefit. However, it is possible to point to some of the effects that are anecdotally reported.

The first set of effects is upon country lawyers themselves, who anecdotally report overwork, and an inability to retire or otherwise adjust their lifestyle as they age. This is in part related to considerations such as the inability to harvest the goodwill of the practices they have built.

The second suite of effects is upon those whose needs are critical and urgent. ${ }^{6}$ Such urgent need is seen particularly in the area of criminal law, the need for which by its nature tends to be greater among the least privileged, either as victims or putative offenders.

The third suite of effects is far more difficult to specify. It is hard to be specific about what it costs a rural community to be unable to access preventative or administrative support services, such as family law and estate advice, advice as to general legal rights and obligations, or any of the other non-urgent and perhaps non-critical needs of people that are typically met through the use of legal advice. Further, it is not possible to specify the effects of limited competition in an area upon the costs and quality of the advice that is available, though first principles would suggest that there is likely to be such an effect.

The specific causes of an inadequate supply of lawyers to meet the needs of more remote communities have been identified in previous studies as including:

1. Inadequate remuneration, due to factors including the incapacity of the rural market to pay, and the types of services that are most required in rural and regional communities;

\footnotetext{
${ }^{6}$ Ibid. See also Mundy, above n 5; Melinda Brown, 'A Country Practice' (2000) 74(9) Law Institute Journal 14; Jeff Giddings, Barbara Hook and Jennifer Nielsen, 'Legal Services in Rural Communities: Issues for Clients and Lawyers' (2001) 26(2) Alternative Law Journal 55 .
} 
2. The effects of competition policy and other reforms on the mix of services, and the resulting inability of rural practitioners to continue to cross-subsidise their more expert services with the income from delegable functions such as conveyancing;

3. Lifestyle considerations, cited by Mundy as being: 'family issues (ties to community, employment opportunities for one's partner, availability of social and support networks for family and educational opportunities for children), lifestyle perceptions, lack of career development opportunities and professional isolation, salary, the changing employment patterns of younger lawyers and the changing demographics within the profession'?

Given these causes of inadequate supply, the types of solution generally proposed tend to focus upon the economic mix, with some concern for the recruitment of young lawyers whose education and lifestyle make comfort with rural practice likely. A variety of strategies are proposed, which it is not necessary to discuss here, as the purpose of this paper is to suggest that, whilst such profession-targeted strategies are almost certainly required, they may still prove to be insufficient unless more systemic interventions are also carried out. It is to this systemic aspect that we now turn our attention.

\section{B Systemic Causes and Effects}

\section{$1 \quad$ Service Issues}

The focus of such strategies is the attraction and retention of lawyers as specialist professionals and the development and maintenance of the skills of these professionals. However, many complex interactions also have an impact on the likelihood of such strategies being effective. One that is ill-documented is the completeness and competence of the network of other professionals upon whom lawyers depend for both commercial and personal services for themselves and their families. These necessary professional networks could include teachers, accountants, financial planners, doctors, podiatrists, counsellors and many other human conduits for the knowledge and skill that is needed for a professional to lead a satisfactory professional and domestic existence. Stories of country lawyers wishing to leave rural communities because of frustration at the unavailability of a good maths teacher for their talented children, or because of their inability to access good medical services, or because they become tired of the lack of complementary services required

\footnotetext{
${ }^{7}$ Mundy, above n 3, 2.
} 
for the proper practice of the law, abound when country lawyers get together. The absence of any part of the web of professionals can have significant impacts on the economic or personal welfare of the rural lawyer, or on the quality of the service and the outcome of the services that are provided to the community.

The proportion of 'professions' in rural workforces is lower than for Australia generally. In 2001, 20 per cent of the urban labour force were professional workers. On the other hand 11 per cent of the labour force in rural/regional areas were professionals. ${ }^{8}$ Rural population decline, coupled with a smaller rural professional workforce demographic, places rural areas under strain. Another consideration is the ageing of the professional workforce, which is not only a matter of raw numbers. In some cases, it is estimated that at least two younger professionals may be required to replace a retiring professional. The senior professional (with a much greater level of experience) may have undertaken a larger and more complicated workload than a junior professional may be willing or even able to do. ${ }^{9}$ The gaps in the web of professions represented in a community are not only represented in the lack of services for that community; they are also important elements in a perverse cycle within which the remaining professionals find themselves having to practise in ways that are increasingly uncomfortable or which increasingly compromise the quality of the service that they feel able to deliver. These same gaps are also key considerations in the quality of life concerns that are often noted.

In considering the effects of professional service disadvantage, the impact that lawyers make in society should also be remembered, an impact extending well beyond the delivery of specific services to particular clients. Lawyers function as catalysts and supporters of a variety of types of innovation in communities, and as contributors to the fabric of respect for law that is at the heart of civil society. This function can be easily under-valued, because it is a 'soft' component in society, but one only needs to look at the role of lawyers in various aspects of social justice innovation to appreciate that this is a role that has value. Community legal services, public interest litigation, and legal action to protect minority interests are all indicative of the social justice innovation role of legal practitioners who have an embedded culture of concern for social justice. From an entirely different perspective, the importance of commercial lawyers in shaping commercial strategies and structures to minimise risks and maximise gains is demonstrated by (if nothing else) the enormous fees that savvy business owners and executives

\footnotetext{
${ }^{8}$ Robert Miles et al, 'The Attraction and Retention of Professionals to Regional Areas' (2006) 12(2) Australasian Journal of Regional Studies 129, 130.

${ }^{9}$ Ibid 140.
} 
are prepared to invest in their advice. The lack of an adequate cohort of country legal practitioners is felt in the fabric of the community, as is the absence of a doctor, nurse, accountant or any of a number of other professionals that are part of the 'normal' composition of more urban communities.

\section{Career Issues}

CSIRO has found that their difficulties in attracting scientists to rural work relate to career issues at least as much as to the lifestyle issues that are commonly discussed by the professions. It is felt by young scientists that their career development would suffer at least in part because of limited professional development. ${ }^{10}$ Much the same was found by Humphreys et al when researching rural general medical practitioners. ${ }^{11}$ Their survey of doctors suggested that the lack of professional support and on-call arrangements spilled over into problems of family welfare and isolation. Similar patterns recur in the research of different professions. ${ }^{12}$ The importance of continuing professional development in creating a sense of 'connection' and peer support is something that seems to be overlooked in the strategies that are generally proposed, but often emerges from dialogue with rural professionals as a significant factor. In the study by White et al, 80 per cent of their respondents indicated that they would be less likely to remain in rural practice without access to continuing education. ${ }^{13}$ For allied health practitioners Stagnitti et al found that the causes of dissatisfaction for young professionals related at least as much to the standards of management and professional support as to other reasons. ${ }^{14}$ In the practice of law, a lack of

\footnotetext{
${ }^{10}$ Romy Greiner and M Allan, 'What Motivates People to Join CSIRO's Remote Laboratories and the Perceived Benefits and Challenges of Living and Working in Remote Locations' (Discussion Paper, Sustainable Ecosystems, Commonwealth Scientific and Industrial Research Organisation, 2001).

${ }^{11}$ John Humphreys et al, 'Workforce Retention in Rural and Remote Australia: Determining the Factors that Influence Length of Practice' (2002) 176(10) Medical Journal of Australia $472,472-6$.

${ }^{12}$ Miles et al, above $\mathrm{n} 8$.

${ }^{13}$ Colin White et al, 'Making a Difference: Education and Training Retains and Supports Rural and Remote Doctors in Queensland' (2007) 7 International Electronic Journal of Rural and Remote Health Research, Education, Practice and Policy $1<\mathrm{http}: / / \mathrm{www} . r \mathrm{rh} .0 \mathrm{rg} . \mathrm{au} /$ publishedarticles/article_print_700.pdf>.

${ }^{14}$ Karen Stagnitti, 'An Exploration of Issues of Management and Intention to Stay: Allied Health Professionals in South West Victoria, Australia' (2006) 35(4) Journal of Allied Health 226, 226.
} 
suitable CPD has also been cited as a significant concern, particularly for younger professionals. ${ }^{15}$ This aligns with our findings, detailed below.

\section{Summary}

Such issues sit alongside the many personal and family issues that have also been discussed in the Mundy literature review. Economic and job-specific considerations are important, but they are not the complete picture of what makes it difficult to attract and retain rural professionals. What has been lacking in many of the reports about how to solve the problem is the attention to the complete person in the context of the complete community. The literature about 'social capital' is at least as relevant to discussions about creating a strong professional cohort in the country as is the literature about practice economics and family life. Considerations such as the availability of air or other transport, the quality of housing, social life (particularly, it seems, for younger female professionals), the degree of cultural flexibility and 'warmth' of a community — these are all relevant to solving the problem. ${ }^{16}$

We do not raise these points as criticism of past and current efforts to find solutions to the challenges of rural practice - either its economic unattractiveness or the domestic quality of life of the practitioner. These problems have been the main focus of strategies that have been proposed to date. Rather, we wish to point out that these strategies, whilst necessary, are likely to prove to be insufficient unless there is sufficient attention also given to the community and system dimensions of the challenge. We would support and expand on the observation of Miles et al that attracting and retaining professional staff in rural areas demands a 'collaborative effort' involving local, state and federal government bodies, and professional bodies and other regional development groups. ${ }^{17}$ Similar themes have been hinted at in other studies. $^{18}$

\footnotetext{
${ }^{15}$ Ian Rumney, 'The Grass is Definitely Greener' (2006) 77(3) Charter 40, 40-2.

${ }^{16}$ See, eg, Humphreys et al, above n 11; Miles et al, above n 8; Maree Adams et al, 'Development of a Questionnaire Measuring Student Attitudes to Working and Living in Rural Areas' (2005) 5 International Electronic Journal of Rural and Remote Health Research, Education, Practice and Policy $327 \quad<\mathrm{http} / / /$ www.rrh.org.au/ publishedarticles/article_print_327.pdf $>$.

${ }^{17}$ Miles et al, above n 8, 147-9.

${ }^{18}$ Planning Professionals Working Group, 'The NSW Planning Profession: Looking Forward Report of the Planning Professionals Working Group to the Minister for Planning' (November 2006) $13<$ http://www.planning.nsw.gov.au/settingthedirection/pdf/ppwg_report_nov06. pdf $>$; Humphreys et al, above n 11.
} 
We would all acknowledge that fulfilment in our lives comes from more than money and family. A fulfilling existence involves many aspects, including the network of fulfilling experiences and relationships that together constitute the social fabric of 'a good life'. Young professionals are intrinsically mobile because they are well-skilled and often have a variety of available choices open to them. They have high aspirations, and do not lack the ability to judge critically what is available to them. The 'total package' has to be sufficient to attract and hold them. Creating such a package involves shaping the social system in which they will carve out a fulfilling life for themselves and their families. This speaks of the need to take a different approach to the ones that have been mainly tried, bringing together the 'receptor' community, networks of professions and government into a more complete addressing of the total challenge.

\section{Our Survey and Workshop}

During 2008, researchers from the University of New England carried out a study to begin to come to grips with these systemic matters. The study involved an online survey, and a 'Rural Professionals Summit' involving representatives of a wide variety of rural professions. Three hundred and thirteen people commenced and 122 completed the survey (38.98 per cent). Not all respondents designated their professions, but the following is the recorded mix of professions.

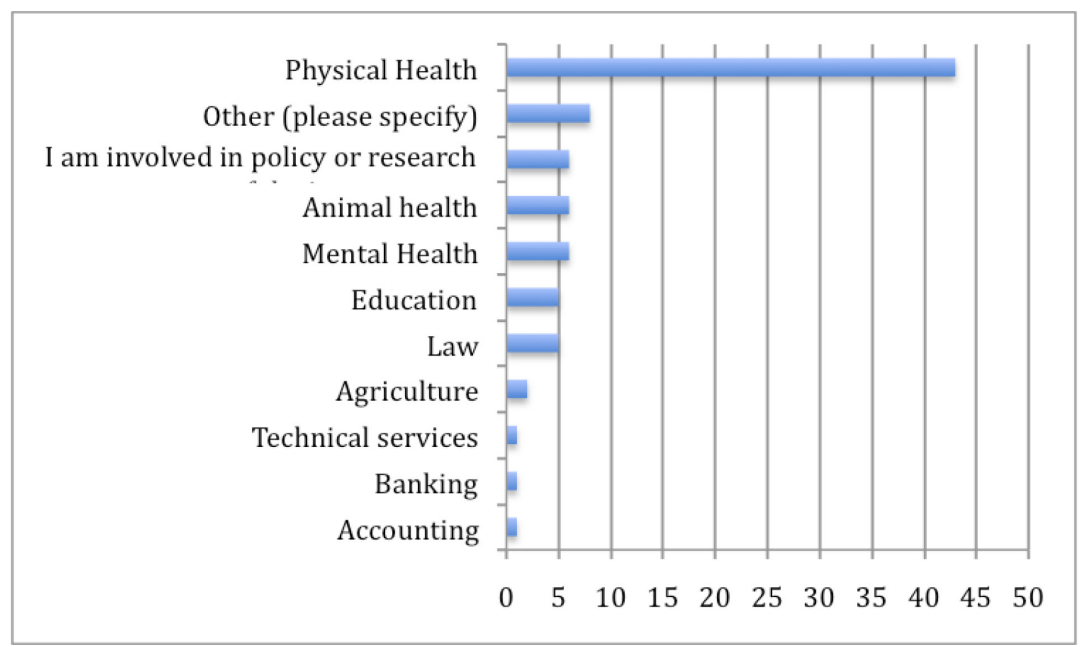


The survey addressed: recruitment and retention, innovation in rural services, networked services delivery, training and education, lifestyle and family, isolation, economic issues, risk issues, gender issues, and opportunities for innovation across all of these (and other) dimensions. It was followed by a full day workshop carried out at Bingara, NSW, which involved representatives of the groups indicated by the following diagram. The focus of the workshop was to identify the key factors relevant to better meeting the professional service needs of rural communities, and the type of research and innovation that would be needed to achieve this end.

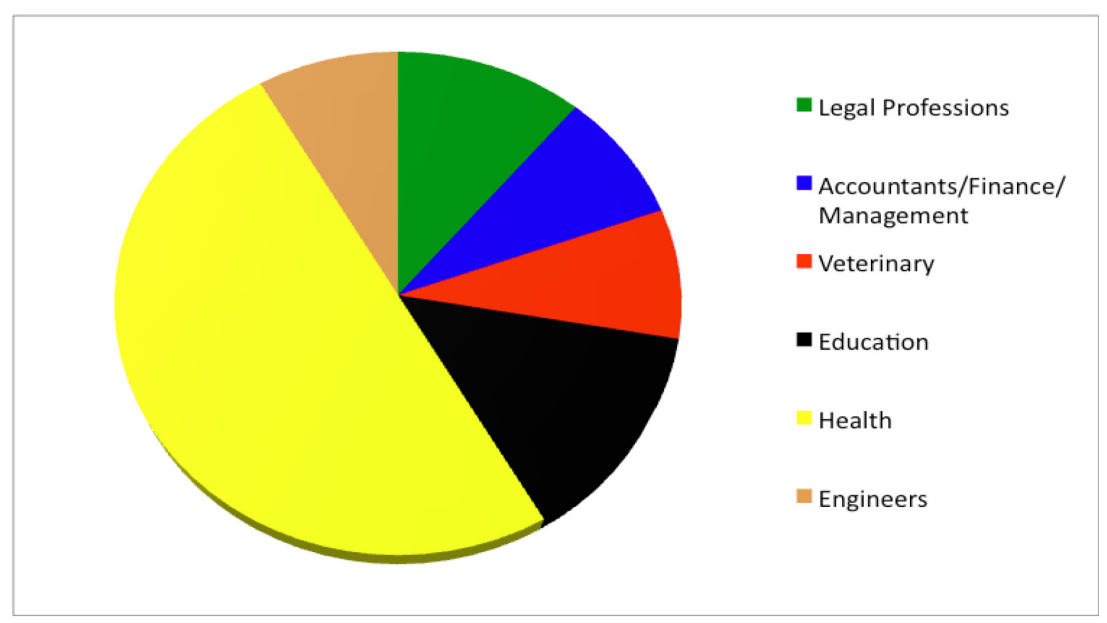

The work reinforced our view that any comprehensive addressing of the issues requires a suite of interrelated 'solutions'. Some solutions are specific to the profession and the professional issues, with an emphasis on the transactions that occur between the practitioner and the client (or patient). These are the matters that are the focus of attention of legal practice organisations, or other professional bodies. However, these solutions are underpinned by a wide variety of transactions of many types - economic, social, recreational, cultural and technical. The issues vary with the type of transaction, but the total quality of the practitioner's experience depends on the quality of the transactions at all levels and of all types.

The following diagram represents the range of matters that were identified through the survey and the Summit as being relevant to a comprehensive strategy to attract and retain a sufficient supply of rural professionals. It also summarises a variety of interventions that might be relevant to 'solving' the identified problems in a more comprehensive and systematic manner. 


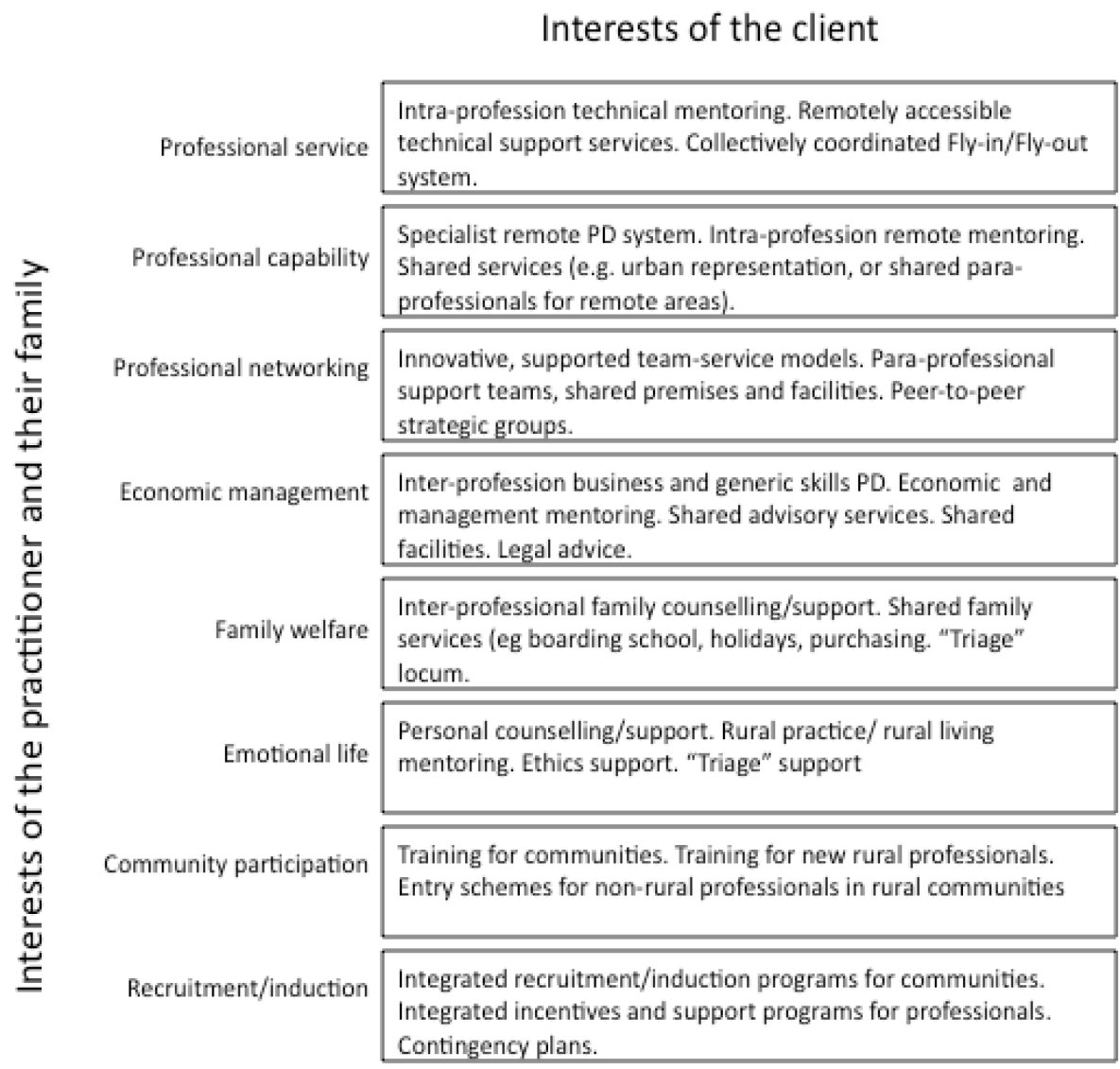

Interests of the community

Across all professions, the 'traditional' focus of interventions is given attention at the apex, emphasising the quality of the professional's addressing of the (technical and interpersonal) concerns of the client. To a lesser degree attention is placed upon the second level — interaction between practitioners and their close family — but little is placed upon the quality and completeness of the networks of professions of different types operating in a community, nor upon the interactions between professionals and the community as a whole.

What is apparent from this discussion is that, just as no professional person can be considered as an island, no particular profession can be considered as an island in addressing this suite of interconnected issues. If we are serious 
about solving the problems, or finding viable service delivery models that reduce the adverse effects of rural isolation, we need to graft onto the present considerations a deep dialogue with other professions, with government, and with rural communities about ways to also address the 'base' of the triangle, as well as its peak, and all points in between.

Fourteen priority research issues were identified out of this research process. They were identified as the matters where better answers would be most likely to contribute to a holistic approach to solving the problems that were identified. These issues were:

1. What is the true social and economic cost of disadvantage in rural access to professional services?

2. What are the specific professional service needs of different types of rural community, and in what configurations are they needed?

3. What innovative methods of supply have been used for professional services in rural remote areas? What have been the successes and failures?

4. What platform of capabilities (knowledge, skill, teams, data, systems) is necessary for effective rural professional services delivery? What strategies are most likely to ensure its availability?

5. What are the capabilities required of graduates, which would improve performance and retention in rural and remote settings? What strategies can enhance these capacities?

6. What innovations or efficiencies can improve continuing professional development participation, effectiveness and efficiency?

7. What incentives are effective in encouraging recruitment and retention to a rural area?

8. What role is there for the community in recruiting and maintaining professional services in rural areas?

9. What is the optimal role for professional associations in supporting rural professionals?

10. Is there a role for rural and regional intra- or inter-professional mentors? 
11. What are the best ways of addressing the emotional or personal needs of the rural professional?

12. What support does the family unit of the rural professional require?

13. What opportunities exist to improve recruitment for rural professional practice?

14. To what extent might reform of rules governing professional practice assist access to professional services?

These are representative of the types of knowledge that would be needed to truly address the total challenge. What readers might note is how different this is to the current suite of research and dialogue that is taking place about the issue of rural professional services.

Research opportunities identified by the Summit included opportunities for research into alternative methods of supply and the extension of the scope of practice (for example through up-skilling). The Summit also suggested the need for an analysis of actual service requirements. Suggestions that were centred upon professional capability development included the suggestion of research into improved accessibility of professional development opportunities, as well as into alternative methods of delivering professional development and mentoring services.

Networking emerged as another area for more intensive research. Suggestions included examining the role of professional associations in networking, reconceptualising the role of mentors (particularly cross-professional mentors), and examining the feasibility of multi-purpose strategic professional centres.

Research relating to economic skills was also suggested, with a possible project cataloguing generic skills required by rural professionals and exploring economic and management mentoring. Family issues presented as another key issue, with participants suggesting a need for research into support for the family unit of the rural professional, including the provision of counselling and educational services. Linked to this was a suggestion for research on the emotional welfare of the professional, and the access to counselling and other support opportunities for non-technical aspects of the rural professional existence. 
Research into the role of the community with respect to the professional is another area of opportunity. It was suggested that there was a need to understand community expectations of what a rural professional will contribute, and the ways in which communities can assist the transition to rural life for new rural professionals (particularly those recently migrated to Australia or not familiar with rural life). The potential for community organisations to form partnerships with professional organisations was also explored.

Various opportunities to facilitate recruitment were explored. Research proposals included demographic analyses of the factors which encouraged rural people to remain in or return to rural areas. As a part of this, research was proposed into: how to promote the professional and personal benefits of working as a rural professional, in addition to the financial benefits of doing so; what attributes are required in a rural professional (identifying the ideal candidate'); how effective current recruitment incentives are, and what opportunities for rural based recruitment specialists exist.

There is a potential for shared support across professions. Such support might include (for example) cross-professional professional development and person-to-person advice on rural-practice ethics problems, management issues, and family welfare. This potential extends to facilitation of networks, facilities, and training of support staff. The potential also involves working with rural communities to attract and retain professionals or to develop coping mechanisms when such strategies are unable to meet the need.

\section{DiRECTIONS towards a Solution}

We are mindful that the picture that this paper paints is that the challenge of ensuring a sufficient supply of legal services in rural areas is more complex than has generally been acknowledged, that the implications of the failure to do so are probably deeper than is usually acknowledged, and that true solutions are not within the scope of any profession itself to create and implement. This is disconcerting, and one possible response from the legal profession is to decide that the larger problem is so great that all that can be done is to focus on what can be done within the profession and hope for the best. At a human level that response is understandable, but in the interests of rural communities and indeed of rural legal practitioners this would be unfortunate. 
Einstein's aphorism that 'no problem can be solved from the same level of consciousness that created it' seems to be relevant to this situation, particularly when joined to Mencken's later observation that 'for every complex problem, there is a solution that is simple, neat, and wrong'. If Australia cannot develop a different and more systemic approach to resolving the issues of rural professional services then it is not likely that these problems will be solved.

Clearly, the pursuit of such a comprehensive approach is beyond the capacity of any one profession. It requires a partnership between professions, and it requires a different, less 'siloed', approach by government in thinking about rural professional workforces. It was suggested at the summit that to obtain the attention of government it is necessary to think about the power of the professions as an institutional grouping, and to take on brave new ideas. It was also suggested that professions collectively may need to challenge the definition of 'professions' and the concept of 'rural', and that alternative funding methods for rural communities should be considered.

This is a political challenge for the legal profession, for it suggests that leadership will require the creation of new coalitions with other professions, and the crafting of a sophisticated multi-dimensioned strategy. It will require action to cause government to re-engage with the needs of rural communities in a less fragmented and more comprehensive manner. Without this leadership it is hard to see how any meaningful solutions will be found. 